\title{
Redesign of Motorized and Non-motorized Transport in Cities and Sustainable Mobility
}

\author{
Osman Lindov $^{1}$, Adnan Omerhodžić ${ }^{1}$, Adnan Tatarević ${ }^{2}$ and Samir Džaferović ${ }^{3}$ \\ 1. Department of Traffic, Faculty of Traffic and Communications, University of Sarajevo, Sarajevo 71000, Bosnia and Herzegovina \\ 2. Department Approval of the Vehicle Type, Institute of Traffic and Communications, Sarajevo 71000, Bosnia and Herzegovina \\ 3. Department for Road and Rail Transport, Ministry of Communications and Transport, Sarajevo 71000, Bosnia and Herzegovina
}

Received: December 21, 2015 / Accepted: January 06, 2016 / Published: March 31, 2016.

\begin{abstract}
Redesign of motorized and non-motorized transport in cities and sustainable mobility possibilities and utilization of already occupied areas for motorized and non-motorized transport in cities. Reserved area for public transport may be the redesign much more to take advantage of without taking up new space in cities. Redesigned solutions shown in the work of public mass transport and the redesign of non-motorized transport, bicycle and pedestrian paths point to the improved use and safety of movement of passengers, cyclists and pedestrians. This paper presents five redesigned concept designs as improving existing forms of transport and movement of cyclists and pedestrians in cities. Redesigned conceptual designs of motorized and non-motorized transport in cities should serve as ideas for the growing problems of urban development in the segment of insufficient surface for pedestrians and cyclists, as well as sustainable mobility transport people in the city.
\end{abstract}

Key words: Redesign, motorized transport, non-motorized transport, sustainable mobility.

\section{Introduction}

Final goal of global directions of the European cities development, including Sarajevo, in the period untill 2023 is a qualitative, comfortable, safe and reliable transport, fully adjusted to the demands of passengers. According to stated plans, planned development of the public passenger transport system shall be based on the inclusion of railway into the passenger transport system, as well as the transformation of the existing tramway passenger service into the system of LRT (light rail transport). These plans have existed for the last 30 years and are planned for the next 30 years. However, from the security and ecologic aspect, cities become "problematic" because certain plans are not fully realized as planned. Those plans did not include the segment of sustainable development that is today the

Corresponding author: Osman Lindov, Ph.D., research fields: traffic safety and environmental traffic. priority. Given the stated, it would be too long to wait for another next 30 years to implement the plans stated in strategic documents. It is necessary to react adequately and promptly, and that it possible only through the innovative and "fresh" solutions that have to be valorized in the cities [1]. Most of developed European cities have action plans and established development strategies for sustainable transport, and they intensively work on informing and educating residents on necessity of transformation of the existing mode of transport into the sustainable one [2]. Experiences of the cities that have already passed the initial phases of project implementation show that, education of residents has to be the first step in fulfilling such goals. Some of the advantages of sustainable transport are: healthier life of residents, less noise, less pollution and nicer city. And if the residents are not familiarized with these facts, and if they do not recognize them as their own, and there is no since if residents are not familiar with these facts, 
and if they do not recognize them [3].

\section{Redesign of Road Profile-Innovative Solutions for Motor, Pedestrian and Bicycle Paths}

In the last 30 years, there were no significant changes in the width of road profile. Both pedestrian and motor traffic, as well as bicycle paths are built at the same level. Innovative solutions propose the construction of the road "above" the level, in other words, to construct the surface for motor transport at the separate level, and to elevate the cycling surface, and then to construct the pedestrian paths above that with pellucid panels above the pedestrian and cycling lane [4]. Such projecting and construction will provide significantly increased road safety (Fig. 1).

\section{Redesign of the Miljacka River Bed-Innovative Solutions for Pedestrian/Bicycle Paths}

Alternative modes of transport in the cities will be required, primarily cycling connected and linked with adequate pedestrian paths, and more detailed and precise planning of free space that will be used for such alternative modes of transport [5]. Redesigning of the Miljacka River bed that stretches from the central part of the city towards the periphery in the total length of $10 \mathrm{~km}$, implies putting into operation the space occupied by the river itself. The redesign itself of the Miljacka River bed will be characterized by the construction of the terraces on the both sides of the river with pedestrian and cycling paths (Fig. 2). The aim of the redesign is to provide new look of the bed with modern and useful paths, without any damage to the river and its importance and role for urban area.

Redesign of the Miljacka River bed will contribute to greater safety of pedestrians and cyclists because it will divide physically separated terraces [6].

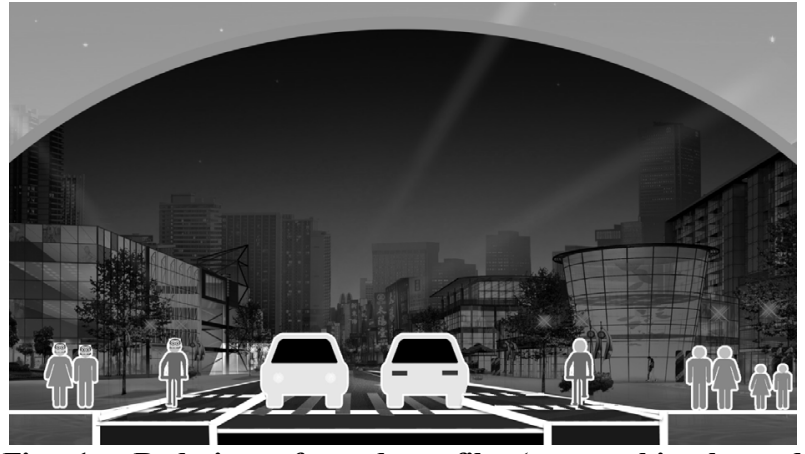

Fig. 1 Redesign of road profile (motor, bicycle and pedestrian paths).

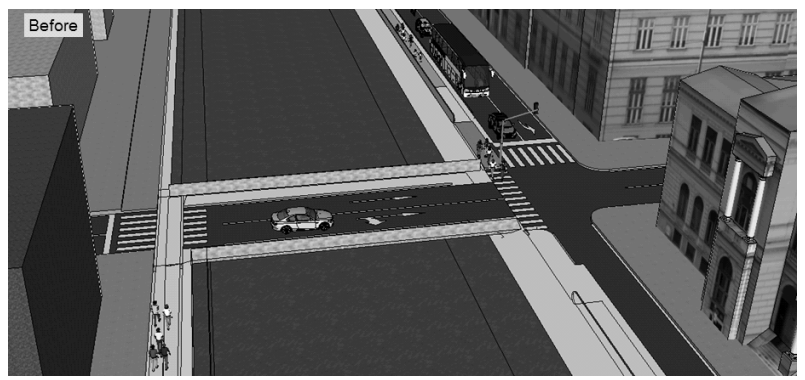

(a)

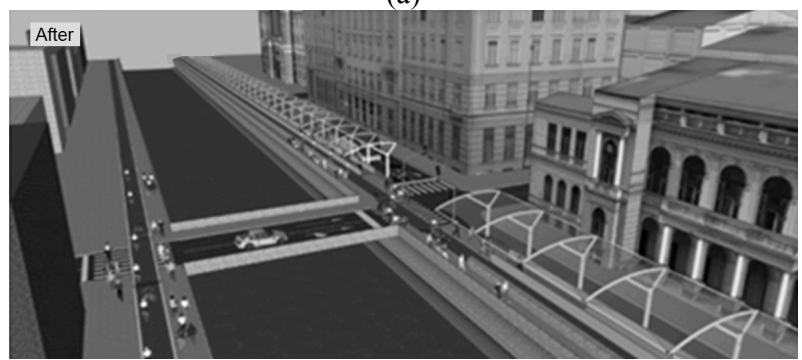

(b)

Fig. 2 Redesigned-innovative solution for Miljacka River bed.

\section{Redesign of Rail Tramway Belt-Innovative Solutions for Tramway Transport}

Occupied belt for tramway transport in Sarajevo is a designed and occupied space used for lower and upper rail machines transport. It currently covers a huge belt and already in the city central parts creates significant problems due to noise emission [7]. Innovative solutions provide solution for tramway transport that will be pleasant and adequate for the environment, where the route of the rail will partly be underground and above the platform there will be 


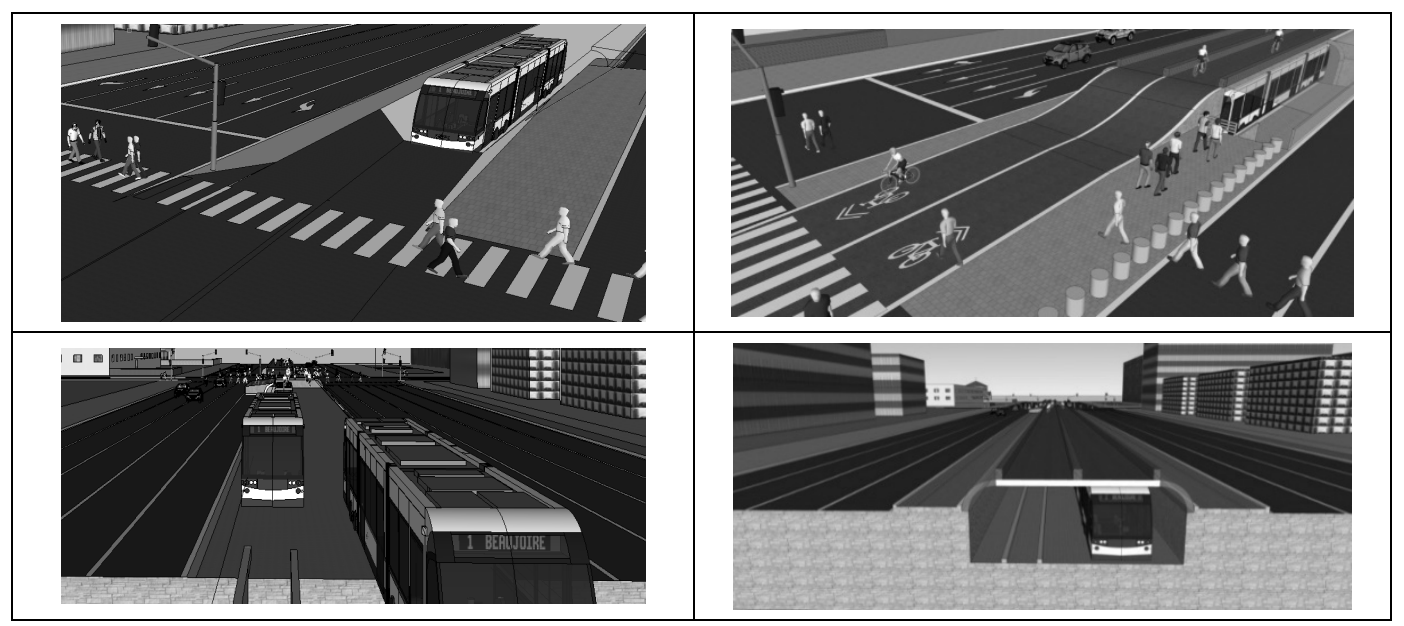

(a) Before

(b) After

Fig. 3 Redesigned-innovative solution for tramway belt.

useful multi-purpose space (bicycles, etc.). Tramway transport in Sarajevo longitudinally stretches for some $14 \mathrm{~km}$ with the belt width from $13 \mathrm{~m}$ to $25 \mathrm{~m}$. Descent of the rail in the ground to the level of tram windows will provide visual contact with the area, avoiding the "unpleasant" feel of the metro and other systems that are completely situated underground. In some parts of the crossroads, this system will be completely situated under the ground and then again to the level of tram windows. This type of solution on the crossroads will secure constant flow of tramway transport, without stopping, which would lead to an increased transport flow and transport safety. The platform above the route may be designed and used for multi-purpose usage, such as pedestrian paths, cycling lanes, as well as the space for emergency services (Fig. 3).

\section{Innovative Type of Transport in the Old Part of Urban Area-Assembly Line}

Since rail vehicles (tramways) inevitably make noise in the areas of their passage, their usage is limited, particularly in the old parts of urban areas [8]. The city of Sarajevo has had, and still has, one of the first tramway system that passes through the old part of the city, and if adequate noise protection standards would be applied, its usage will be prohibited in that part of the city. The alternatives are trolleybus or bus networks. Beside the noise, the cities also face with spatial and environmental pollution issues. Travelators (moving pavement) will be placed along the space of the existing tramway rails and it would have secured space, physical divided from the vehicle traffic, with pellucid panels visually and reasonably in harmony with the travelors lane. In the crossroads, in other words, in parts where motor traffic intersects the streets with travelors, adequate crossings have to be put in place in order to secure pleasant crossing to the other part of the trailor, and thus ensure nice, comfortable and safe transport along the entire length of the rail (Fig. 4).

\section{Pedestrian Zone Redesign-Innovative Solutions for Pedestrian Routes}

Redesigning in pedestrian zones - pedestrian routes innovative solutions, as initial and final solution, envisage an increase in time that pedestrians spend in the pedestrians zones due to different weather conditions (sunshine, rain, snow, etc.). This innovative solution includes roofing the pedestrian zones. That would include of pleasant transparent panels that will be used as protection against sun, rain and other weather conditions. These panels will also be movable and placed above the pedestrian zone in the bad weather conditions (sun, rain or snow). This would affect the increased flow of pedestrians daily and throughout the year, that would lead to a decrease in 


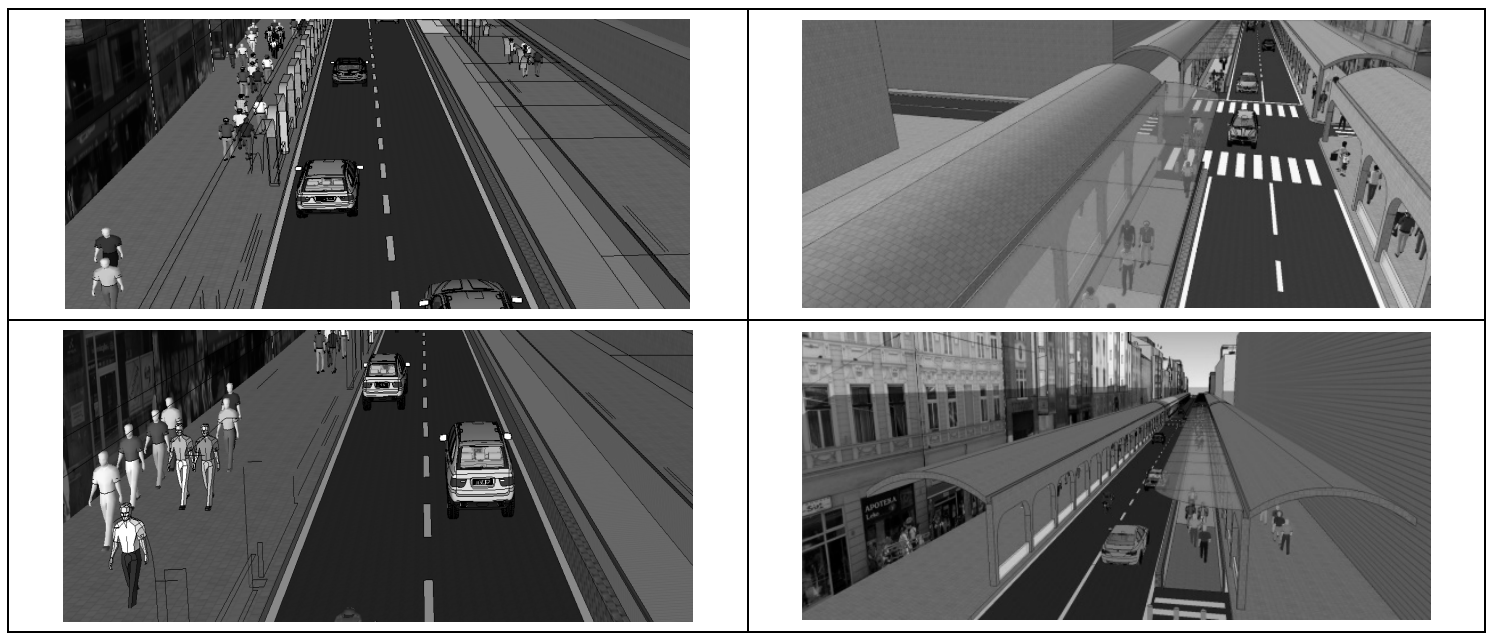

(a) Before

(b) After

Fig. 4 Innovative solution for transport in old part of city-moving walkway.

movement and use of motor vehicles in that part of the city. Day which will, again, decrease the movement and usage of motor vehicles in that part of the city. At the same time, cleaner, nicer, more pleasant, more human and safer city would be provided (Fig. 5).

In the central city zone, where pedestrian paths are situated alongside the main city road, there is a

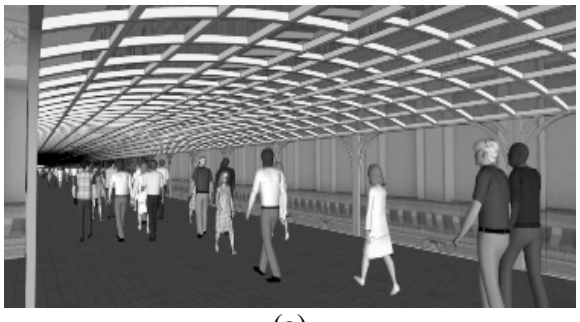

(a)

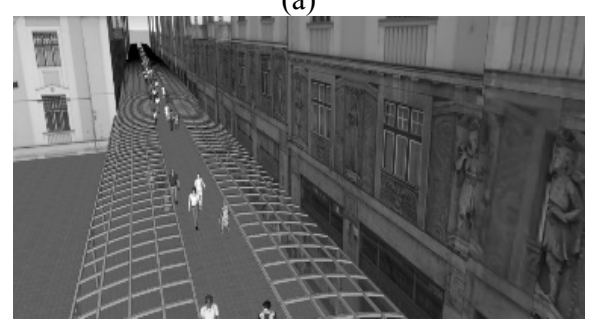

(b)

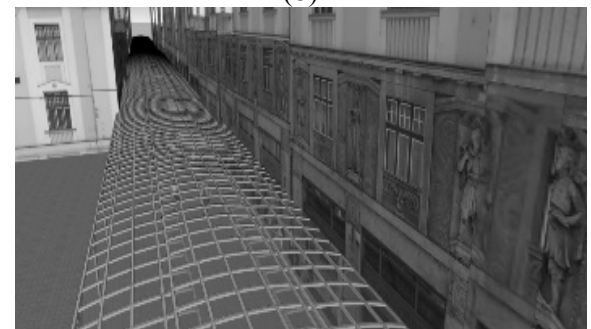

(c)

Fig. 5 Redesign-innovative solution for pedestrian path.

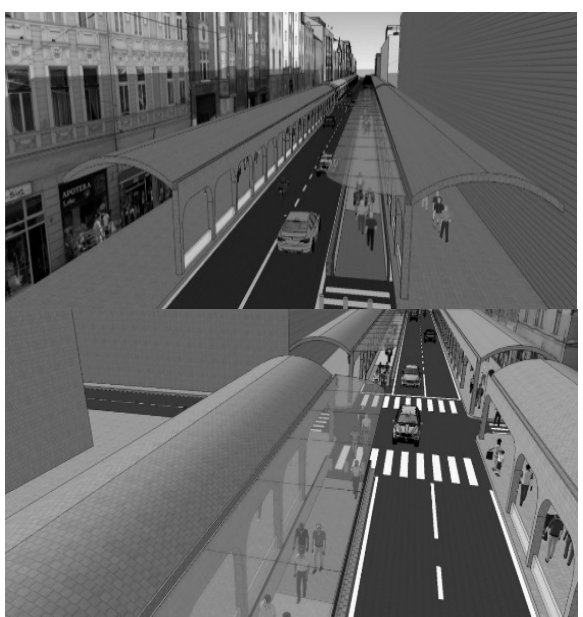

Fig. 6 Redesign-innovative solution for pedestrian path alongside the road.

possibility to build adequately designed domes or arches above the pedestrian routes that would be adjusted to the buildings the arches would be connected to. The building with which the arches will be connected (Fig. 6).

\section{Conclusions}

Redesigned, or in other words, innovative solutions for traffic and transport flows, are impracticable in the short run, mostly as result of slow changes of standards in designing and construction. Redesigned and innovative solutions presented in this paper, authors' incentives to consider them as possible solutions in urban areas from the aspect of sustainable 
development of cities worldwide.

Most of transport solutions today are "classic" and expensive, and there is almost no place for innovative and "non-standard" solutions.

Certainly, each of solutions described in this work is not new and the once that cannot be used elsewhere. Also, technologies presented in this work for certain solutions are not unknown nowadays, they are only being applied in other fields and purposes. Authors are aware that, each of the presented solutions may be improved and further developed along with the technological development.

\section{Reference}

[1] Organisation for Economic Co-operation and Development. 2002. "Implementing Sustainable Urban Travel Policies, Key Messages for Governments." In Proceedings of the ECMT (European Conference of Ministers of Transport), 13-8.

[2] Archer, J. 2005. Indicators for Traffic Safety Assessment and Prediction and Their Application in Micro-simulation Modelling: A Study of Urban and Suburban Intersections.
Stockholm: Royal Institute of Technology.

[3] International Engineering and Consulting Group SYSTRA (Systèmes de Transport, Transport Systems). 2009. "A Study of Optimization of the City Transport Network and Making Long-Term Plan for Transport Canton Sarajevo." International Engineering and Consulting Group SYSTRA.

[4] Lindov, O., and Omerhodžić, A. 2013. "Analysis of Efficiency of Road Traffic Improvement Measures-Local Activities and Best International Practice." Suvremeni Promet-Modern Traffic 33 (1-2): 262-7.

[5] Stokić, D. 2009. "Education of Citizens-The Main Precondition for Sustainable Transport." Faculty of Civil Engineering and Architecture in Nis, Science + Practice 12 (1): 224.

[6] Lindov, O., Omerhodžić, A., Tatarević, A., and Džaferović, A. 2015. "Redesign of Motorized and Non-motorized Transport in Cities and Sustainable Mobility." Presented at the International Conference "Towards a Human City", Vojvodina, Novi Sad.

[7] Lindov, O., Tatarević, A., and Džaferović, S. 2013. "Modern Methods of Road Audits in Order to Increase Traffic Safety." Suvremeni Promet-Modern Traffic 33 (1-2): 277-82.

[8] Lindov, O. 2012. "Traffic Culture." Faculty of Traffic and Communication of the University of Sarajevo. 